\begin{tabular}{cc|c}
\hline Tar. Bil. Der. & Journal of Agricultural Sciences \\
& $\begin{array}{c}\text { Dergi web sayfası: } \\
\text { www.agri.ankara.edu.tr/dergi }\end{array}$ & Journal homepage: \\
& www.agri.ankara.edu.tr/journal
\end{tabular}

\title{
Fotovoltaik ve Termal Güneş Enerjili Sürekli Bir Kurutucuda Domates Kurutulması
}

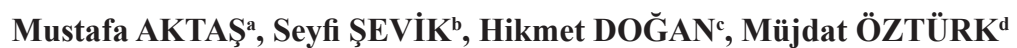 \\ ${ }^{a}$ Gazi Üniversitesi, Teknoloji Fakültesi, Enerji Sistemleri Mühendisliği Bölümü, Teknikokullar, Beşevler, Ankara, TÜRKIYE \\ ${ }^{b}$ Gazi Üniversitesi, Ostim Meslek Yüksekokulu, Elektrik ve Enerji Bölümü, Ostim, Ankara, TÜRKIYE \\ ${ }^{c}$ Gazi Üniversitesi, Teknik Eğitim Fakültesi, Makine Eğitimi Bölümü, Teknikokullar, Beşevler, Ankara, TÜRKIYE \\ ${ }^{d}$ Ahi Evran Üniversitesi, Kaman Meslek Yüksekokulu, Makine Bölümü, Kaman, Kırşehir, TÜRKIYYE
}

ESER BILGİí

Araştırma Makalesi - Tarım Teknolojileri $\quad$ DOI: 10.1501/Tarimbil_0000001217

Sorumlu Yazar: Seyfi Şevik, E-posta: seyfisvk@hotmail.com, Tel: +90 (312) 2028707

Geliş Tarihi: 20 Aralık 2012, Düzeltmelerin Gelişi: 5 Şubat 2013, Kabul: 20 Şubat 2013

\section{ÖZET}

$\mathrm{Bu}$ çalışmada, güneş enerjili $10 \mathrm{~kg}$ kapasiteli bir kurutucu tasarlanmış, imal edilmiş ve domates kurutularak analiz edilmiştir. Geliştirilen kurutucu farklı şartlarda domates kurutmak için kullanılmıştır. Gerekli olan elektrik ve 1S1 enerjisi tamamıyla güneş enerjisiyle sağlanmıştır. $5 \mathrm{~mm}$ kalınlığında dilimlenmiş domatesler, $16.39 \mathrm{~g}$ su g kuru madde ${ }^{-1}$ başlangıç nem miktarından $0.21 \mathrm{~g}$ su g kuru madde ${ }^{-1}$ son nem miktarına düşünceye kadar kurutulmuştur. Domates dilimleri; $40^{\circ} \mathrm{C}, 45^{\circ} \mathrm{C}$ ve $50{ }^{\circ} \mathrm{C}$ kurutma havası sıcaklıklarında ve ortalama $0.2 \mathrm{~m} \mathrm{~s}^{-1}$ hava hizında sirasılyla $8.5,7$ ve 6 saat sürede kurutulmuştur. Özgül nem çekme oranı (SMER) değerleri $40^{\circ} \mathrm{C}^{\prime} \mathrm{de} 0.49 \mathrm{~kg} \mathrm{kWh}{ }^{-1}, 45^{\circ} \mathrm{C}^{\prime} \mathrm{de} 0.45 \mathrm{~kg} \mathrm{kWh}^{-1}$ ve $50{ }^{\circ} \mathrm{C}^{\prime} \mathrm{de} 0.42 \mathrm{~kg} \mathrm{kWh}^{-1}$ olarak hesaplanmıştır. Deney sonuçlarına göre, güneş kolektörü verimi ortalama $\% 49.33$ olarak hesaplanmıştır.

Anahtar Kelimeler: Kurutma; Güneş enerjisi; Domates; Enerji analizi

\section{Drying of Tomato in a Photovoltaic and Thermal Solar-Powered Continuous Dryer}

\section{ARTICLE INFO}

Research Article - Agricultural Technologies

Corresponding Author: Seyfi Şevik, E-mail: seyfisvk@hotmail.com, Tel: +90 (312) 2028707

Received: 20 December 2012, Received in Revised Form: 5 February 2013, Accepted: 20 February 2013

\begin{abstract}
In this study, a solar energy dryer capacity of $10 \mathrm{~kg}$ has been designed, manufactured and analyzed by drying tomato. The developed dryer has been used to dry the tomatoes at the different conditions. The necessary electricity and heat energy was provided by solar energy completely. The tomatoes were sliced into $5 \mathrm{~mm}$ thickness were dried from initial moisture content $16.39 \mathrm{~g}$ water $\mathrm{g}$ dry matter $^{-1}$ to final moisture content $0.21 \mathrm{~g}$ water $\mathrm{g}$ dry matter ${ }^{-1}$. Tomato slices were
\end{abstract}


dried at $40{ }^{\circ} \mathrm{C}, 45{ }^{\circ} \mathrm{C}$ and $50{ }^{\circ} \mathrm{C}$ drying air temperatures and average $0.2 \mathrm{~m} \mathrm{~s}^{-1}$ air velocity in $8.5,7$ and 6 hours,

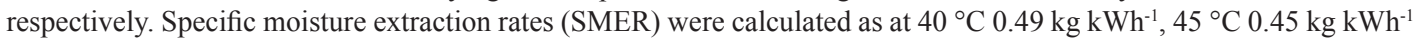
and $50{ }^{\circ} \mathrm{C} 0.42 \mathrm{~kg} \mathrm{kWh}^{-1}$. Average solar collector efficiency was calculated as $49.33 \%$ according to experimental results.

Keywords: Drying; Solar energy; Tomato; Energy analysis

(C) Ankara Üniversitesi Ziraat Fakültesi

\section{Giriş}

Kurutma işi, ürünlerin kaliteli bir şekilde uzun süre saklanabilmeleri için nem miktarının belli değerlere indirilmesi gerekliliğinden yola çıkmış ve bugün gıda başta olmak üzere endüstrinin pek çok alanında kullanılır duruma gelmiştir. Kurutma, genel itibariyle bir ürünün içerisindeki suyu belli sürede istenilen değere düşürmek olarak tanımlanabilir. Kurutma, klasik ve teknik kurutma olarak sinıflandırılacak olursa; klasik kurutmaya en iyi örnek güneşe sererek yapılan kurutmadır. Güneşe serilerek tabii olarak yapılan kurutmada değişkenler (bağıl nem, sıcaklık, hava hareketi ve ürünün temizliği vb.) kontrol altında tutulamadığından; ürünün kalitesi düşmektedir. $\mathrm{Bu}$ da insan sağlığını olumsuz yönde etkilemektedir. Günümüzde ürünlerin steril ortamda, daha teknik metotlarla kurutulması iç ve dış piyasadaki değerini daha da arttıracaktır. $\mathrm{Bu}$ nedenle; modern toplumlardaki yönelim, teknik kurutmaya doğrudur. Bunun yanında, teknik metotlar ile kurutma yapılırken ekonomik ve kaliteli olmasına da dikkat edilmelidir. Bu noktada enerji, en büyük kalemi oluşturduğundan alternatif enerji kaynaklarının kullanımına yönelim artmaktadır. Kurutma konusunda en çok kullanılan alternatif enerji kaynağı güneş enerjisidir. Güneş enerjili sistemler basit teknolojiye sahip olmaları ve güneş enerjisinden doğrudan faydalanmaları nedeniyle kurutmada kolaylıkla kullanılabilmektedir.

Türkiye, coğrafi konumu sebebiyle güneş enerjisinden oldukça verimli bir şekilde faydalanılabilmesi gereken bir ülkedir. EIE verilerinde Türkiye'de yıllık toplam güneşlenme süresinin 2640 saat (günlük ortalama 7.2 saat) ve 1şınım şiddetinin $1311 \mathrm{kWh} \mathrm{m}^{-2} \mathrm{y}^{l^{-1}}$ (günlük ortalama $3.6 \mathrm{kWh} \mathrm{m}^{-2}$ gün $^{-1}$ ) olduğu belirtilmiştir. Türkiye'de, yılda ortalama 110 gün güneş enerjisinden faydalanılabilir. Ayrıca, gerekli yatırımların yapılmas1 durumunda ortalama $1100 \mathrm{kWh} \mathrm{m}^{-2} \mathrm{y}_{1}^{-}$ 1 elektrik enerjisi üretilmesi de mümkündür (EİE 2011). Yapılan ölçümlere göre, Türkiye'nin \% 63 'ünde 10 ay, \% 17'sinde ise 1 y1l boyunca güneş enerjisi ile yapılan uygulamalardan yararlanılabilir. Özellikle güney bölgelerinde, sıcak su elde etmek amacıyla kullanılan güneş kolektörleri gün geçtikçe artmaktadır (Çıtıroğlu 2000).

Güneş enerjisi sistemleri; elektrik üreten (PV), sicak su-hava üreten (1sıtma, kurutma vb. için) ve soğutma sistemleri olmak üzere genel itibariyle üçe ayrılabilir. Dünya'da hâlihazırda işletmede olan düz kolektör ve vakum kolektör toplam kapasitesi içerisinde üst sıralarda yer alan Türkiye (2007 yılı sonu itibariyle $7.1 \mathrm{GWh}_{\mathrm{t}}$ ), bir güneş ülkesidir. Türkiye, fotovoltaik paneller için de son derece elverişli bir güneş enerjisi kullanım potansiyeline sahiptir (Şevik 2011). Sicak su-hava veya elektrik üreten güneş enerjisi sistemleri ayrı ayrı veya birlikte kullanılabilmektedir. Ancak bu tür güneş enerjisi sistemlerinin yalnızca sıcak su üretme ve kurutma amaçı olarak sıklıkla kullanıldığı görülmektedir.

Türkiye'de güneş enerjisi, kurutma alanında oldukça verimli bir şekilde kullanılabilir. Güneş enerjili kurutma sistemlerinin ilk kurulum ve işletme maliyeti dışında önemli masraflarının olmaması ve kullanılan enerjinin tamamının bedava olması, kurutma uygulamaciları cezbeden unsurlar arasında sayılabilir. Bu bağlamda yapılan bu çalışmada, kendi enerjisini üreten ve depolayan bir sistem tasarlanarak imal edilmiş ve deneylerde domatesin daha kaliteli ve ekonomik olarak kurutulmas1 amaçlanmıştır. Ürün seçiminde, Türkiye'nin domates üretiminde dünyada dördüncü sırada olması ve ihracat bakımından domatesin önemli bir yere sahip olması da etkili olmuştur. 
Daha önce yapılan çalışmalar incelendiğinde; Okuyan (1997) güneş enerjisiyle, meyve ve sebzelerin kurutulması üzerine geliştirilen farklı teknolojik sistemleri incelemiş ve bu sistemlerin önemini ortaya koymuştur. Gallali et al (2000) üzüm, incir, domates ve soğanın doğal ve güneş enerjili kurutma sisteminde kurutulmasıyla kül içeriği, nem, ekşilik, toplam şeker azalımı ve $\mathrm{C}$ vitamini gibi bazı kimyasal özelliklerini incelemişlerdir. Kurutulan ürünlerin doğal kurutmaya göre incelenen bütün kalite özellikleri için daha yüksek uygunluk gösterdiğini tespit etmişlerdir. Mengeş (2001) çalışmasında, Konya Bölgesi'nde yetiştirilen vişne ve kayısıların kuruma karakteristiklerini inceleyerek hava sıcaklığı ve hızı arttıkça kurutma süresinin kısaldığını belirtmiştir. Pek çok araştırmacı, raflı kurutucuda (El-Sebaii et al 2002; Mutlu 2007), tünel kurutucusunda (Lutz et al 2003; Saçılık et al 2006), sicak hava kurutucusunda (Giovanelli et al 2002; Doymaz 2007), dondurarak kurutma yapan kurutucuda (Chang et al 2006) olmak üzere farklı tasarımlar ile domatesi kurutmuş ve domatesin kuruma performanslarını incelemişlerdir. Son yıllarda farklı şartlarda kurutulmuş domatesin kurutma sonrası kalitesi ile ilgili pek çok çalışma yapılmıştır (Giovanelli et al 2002; Al-Muhtaseb et al 2010; Cernișev 2010; Santos-Sánchez et al 2012; Demiray et al 2013).

Midilli \& Küçük (2003), doğal ve zorlanmış taşınımlı güneş enerjili kurutucuda, kabuklu ve kabuksuz fistık örneklerinin kuruma davranışlarının matematiksel modellerini ortaya koymuşlardır. Aktaş et al (2004) enerji maliyeti düşük, sıcaklık, nem ve ağırlık kontrollü güneş enerjili bir kurutma firını tasarlamışlardır. Aktaş et al (2005), fındığın kuruma şartlarını göz önünde bulundurarak sıcaklık, nem ve ağırlık kontrollü nem yoğuşmalı bir kurutma fırını modellemesini yapmışlardır.

$\mathrm{Bu}$ çalışmada literatürden farklı olarak, güneş enerjili kurutma sistemlerinde hem güneşten 1S1 enerjisi üreten hem de elektrik enerjisi üreten, aynı zamanda bu enerjiyi depolayarak 24 saat (gecegündüz) çalışabilecek bir sistem tasarımı yapılmış ve sistem domates kurutularak test edilmiştir.

\section{Materyal ve Yöntem}

Kurutma işleminde gerekli enerji miktarının hesaplanması için kurutma odasında harcanan ve kaybolan ısılar aşağıda sırası ile verilmiştir. Başlangıçta, firın duvarlarının sistem kurutma havası sıcaklığına kadar 1sıtılması ve devamlılığ için gerekli 1s1 enerjisi;

$$
q_{1}=m_{1} \cdot c_{1} \cdot \Delta T
$$

Kurutma havasının 1sıtılması için gerekli enerji;

$$
q_{2}=V \cdot c_{2} \cdot \rho \cdot \Delta T
$$

Kurutulacak domateslerin 1sitılması için gerekli enerji;

$$
q_{3}=m_{d} \cdot c_{3} \cdot \Delta T
$$

Domateslerdeki nemin buharlaştırılması için gerekli enerji;

$$
q_{4}=m_{s u} \cdot r_{o}
$$

Fırından çevre havasına olan 1Sı kayıplarını karşılamak için harcanan enerji;

$$
q_{5}=K \cdot A \cdot\left[\frac{\left(T_{k}+T_{i c}\right)}{2}-T_{d}\right] Z
$$

Eşitlikteki toplam 1sı geçiş katsayısı (K);

$$
\frac{1}{K}=\frac{1}{\alpha_{i \zeta \zeta}}+\frac{1}{\alpha_{d i \xi}}+\frac{d_{1}}{\lambda_{1}}+\frac{d_{2}}{\lambda_{2}}+\cdots \cdots \cdots \cdots+\frac{d_{n}}{\lambda_{n}}
$$

ile hesaplanmıştır (Ashrae 1993; Pitts 1977).

Kurutma odasında domateslerin kurutulması için sistemde harcanan toplam enerji miktarı $\left(Q_{V T O P}\right)$;

$$
Q_{V T O P}=q_{1}+q_{2}+q_{3}+q_{4}+q_{5}
$$

ifadesi ile yani firında kurutma için gerekli olan ısıların toplanması ile hesaplanmıştır.

Sistemde güneş kolektörü tarafindan isıtılan sıcak su deposunda depolanan enerji $\left(Q_{d}\right)$ ve kurutma için harcanan enerji $\left(Q_{h}\right)$ toplanarak sistemde elde edilen toplam enerji;

$$
Q_{T}=Q_{d}+Q_{h}
$$


eşitliği ile bulunmuştur. Güneş kolektöründen birim zamanda elde edilen enerji;

$$
\dot{Q}=\dot{m} \cdot c \cdot \Delta T
$$

Güneş kolektörünün verimi ise;

$$
\eta=\frac{\dot{Q}}{F_{K} I_{T O P}}
$$

eşitlikleri ile hesaplanmıştır (Shariah 2002). Özgül nem çekme oranı (SMER), üründen $1 \mathrm{~kg}$ su alabilmek için kurutucuda harcanan enerjidir. SMER değeri;

$$
S M E R=\frac{m_{s u}}{Q_{h}}
$$

ile hesaplanmıştır. Kurutma hızı (DR) değerleri aşağıdaki formülden hesaplanmıştır.

$$
D R=\frac{M_{t+d t}-M_{t}}{d t}
$$

Numunenin ayrilabilir nem oranı (MR) ve ürünlerdeki kuru esasa $\left(\mathrm{MC}_{\mathrm{KA}}\right)$ ve yaş esasa $\left(\mathrm{MC}_{\mathrm{YA}}\right)$ göre hesaplanan nem içeriği değerleri aşağıdaki formüllerden hesaplanmıştır (Ceylan \& Aktaş 2008; Aktaş 2007).

$$
\begin{aligned}
& M R=\frac{M-M_{e}}{M_{0}-M_{e}} \\
& M C_{K A}=\frac{Y A-K A}{K A} \\
& M C_{Y A}=\frac{Y A-K A}{Y A}
\end{aligned}
$$

Belirsizlik analizi, hata analizi için hassas bir yöntem olarak kullanılmaktadır. Deneysel çalışmalarda elde edilen deneysel veriler için önemli bir nokta ise ölçülen değerlerin doğruluğudur. Doğruluğu etkileyen en önemli etken ise, deneyler sırasında farklı nedenlerden ortaya çıkabilecek hatalardır. Yapılan bu deneysel çalışmada bir parametrenin ölçülmesinde, sabit hatalar, rastgele hatalar ve imalat hataları nedeniyle ortaya çıkan hatalar dikkate alınarak toplam hata
$W_{R}=\left[\left(\frac{\partial R}{\partial x_{1}} w_{1}\right)^{2}+\left(\frac{\partial R}{\partial x_{2}} w_{2}\right)^{2}+\ldots \ldots \ldots \ldots \ldots+\left(\frac{\partial R}{\partial x_{n}} w_{n}\right)^{2}\right]^{1 / 2}$

eşitliği ile hesaplanmıştır (Kavak Akpınar 2010).

Eşitlik 16'da R ölçülmesi gereken büyüklük, bu büyüklüğe etki eden $\mathrm{n}$ adet bağımsız değişkenler ise $\mathrm{x}_{1}, \mathrm{x}_{2}, \mathrm{x}_{3}, \ldots \mathrm{x}_{\mathrm{n}}$ şeklindedir. Her bir bağımsız değişkene ait hata oranları $\mathrm{w}_{1}, \mathrm{w}_{2}, \mathrm{w}_{3}, \ldots \mathrm{w}_{\mathrm{n}}$ ve $\mathrm{R}$ büyüklügüünü toplam belirsizliği $\mathrm{W}_{\mathrm{R}}$ 'dir.

\subsection{Deneysel çalışma}

Kurutma işlemlerinde ürünün kalitesi kurutma havasının hızı, sıcaklığı ve bağıl nemi gibi önemli değişkenlerin uygun şekilde ayarlanmasına bağlıdır. Sayılan bu değişkenlerin uygun ayarlanmaması durumunda ürünler daha uzun sürede kalitesiz olarak kuruyabilmektedir. Benzer şekilde yüksek bağıl nem ve düşük hava hızı, kurutma süresinin uzamasına ve buna bağlı olarak enerjinin fazla tüketilmesine neden olmaktadır. Yukarıda belirtilen değişkenlerin domates kurutma işlemi için uygun olarak belirlenip, sistemde daha az enerji harcandığı, ilk yatırım maliyeti dışında masrafı olmayan, kendi enerjisini üreten güneş enerjisi destekli bir kurutma firını tasarlanarak imal edilmiştir.

Kurutma işlemi için gerekli enerji miktarı Eşitlikler 1-7 kullanılarak hesaplanmıştır. Buna göre kurutma sistemi için Ankara İli şartlarında güneş kolektörü yüzey alanı, güneş pili gücü, inverter gücü, fan debisi, 1sitıcı serpantin kapasitesi ve pompa gücü hesaplanmıştır. Sistemin gece ve güneş enerjisinin yetersiz olduğu zamanlarda 1s1 ve elektrik ihtiyacını karşılamak için gerekli akü kapasitesi ve sicak su deposu hacmi tasarlanan bu sisteme göre hesaplanmıştır.

Kurutma firını; pompa, selenoid valfler, eksenel fan, termostat, kurutma kabini, ısı değiştirici, güneş pilleri, akü, invertör, güneş kolektörü ve termometre gibi kısımlardan oluşmaktadır. Tasarımı ve imalatı yapılan güneş enerjili sürekli kurutucu Şekil 1'de gösterilmiştir.

Kurutucunun enerji ihtiyac1, güneş kolektöründen (1s1 enerjisi olarak) ve güneş pillerinden (elektrik enerjisi olarak) sağlanmaktadır (Şekil 2). Güneş 


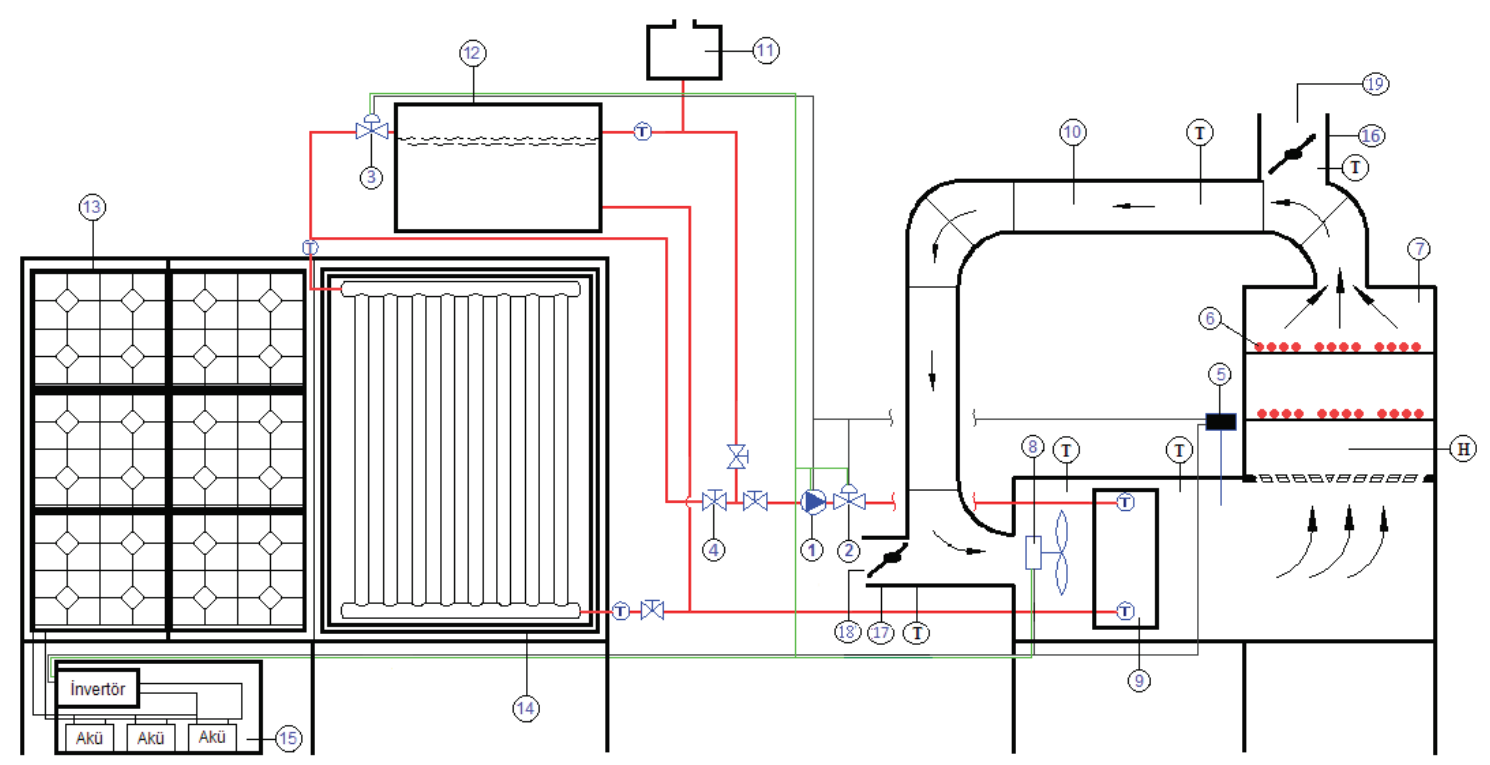

Şekil 1-Güneş enerjili kurutucu: 1, sirkülasyon pompası; 2, selenoid vana (nk); 3, selenoid vana (na); 4, küresel vana; 5, termostat; 6, raf; 7, kurutma fırını; 8, fan; 9, ıSı değiştirici; 10, hava kanalı; 11, açık genleşme deposu; 12, su deposu; 13, fotovoltaik paneller (pv); 14, sıcak su kolektörü; 15, elektrik panosu; 16, hava ayar klapesi (çıkış); 17, hava ayar klapesi (giriş); 18, giriş havası; 19,egzoz havası

Figure 1- Solar energy dryer:1, circulation pump; 2, selenoid valve; 3, selenoid valve; 4, valve; 5, thermostat; 6, shelf; 7, drying cabinet; 8, fan; 9, heat exchanger; 10, air duct; 11, expansion tank; 12, water tank; 13, photovoltaic panels (pv); 14, hot water collector; 15, electrical panel; 16, air adjustment valve; 18, inlet air; 19, exhaust air

kolektöründe ısınan suyun dolaşımı, sirkülasyon pompası vasıtasıyla sağlanmaktadır. Isı değiştirici üzerinden geçerken isınan hava kurutma odasına gitmektedir. Kurutma firını içerisindeki ürünlerin nemi, buharlaşarak kurutma havasına karışmaktadır. Fırında üründen nemi bünyesine alan kurutma havas1 $\% 50$ oranında egzoz edilmekte ve \% 50'si de dış hava ile karıştırılarak tekrar kurutma sistemine gönderilmektedir. Havanın tamamı dışarıya atılmadığ için sistemde enerji tasarrufu sağlanmaktadır.

PV sistemi; pompa, fan ve selenoid valfleri sürekli çalıştırabilecek şekilde tertiplenmiştir. Gündüz sistemin çalışması için gerekli olan elektrik enerjisini sağlayan güneş panelleri, fazla olan elektrik enerjisini akülere aktarmaktadır. Bununla birlikte 1s1 enerjisini sağlayan güneş kolektörü, otomatik kontrolle, fazla 1s1 enerjisini sirkülasyon pompası yardımıyla su

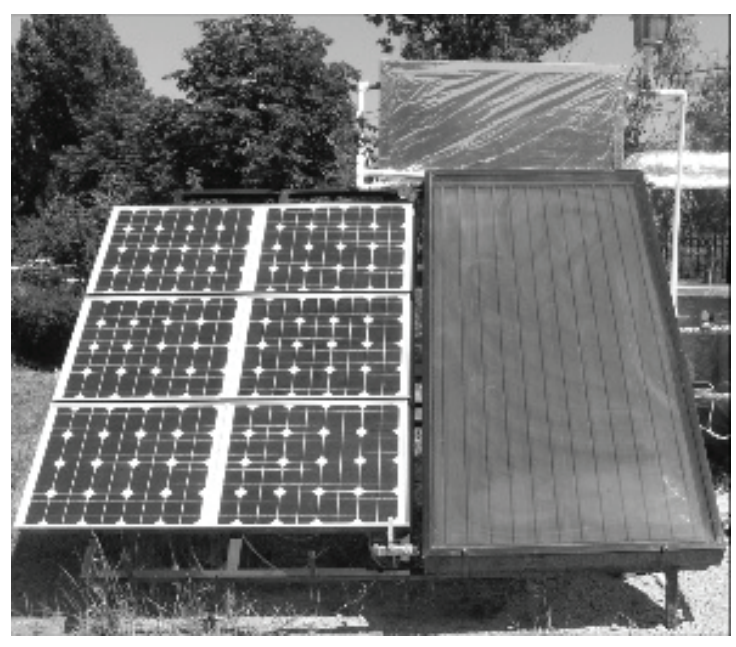

Şekil 2- Isı ve elektrik üreten güneş enerjisi sistemi

Figure 2-Solar energy system that produces heat and electricity energy 
deposundaki suya yüklemektedir. Böylece fazla enerji, gece ve güneşin olmadığı ya da havanın bulutlu olduğu durumlarda kullanılmak üzere depo edilmiş olmaktadır. Gündüz sistemin hem çalışması hem de enerjinin depolanması işleminin otomatik olarak yapilmasi termostat ve selenoid valfler ile oluşturulan kontrol sistemi ile gerçekleştirilmektedir.

Sirkülasyon pompası ve fan bir termostat tarafindan kontrol edilmektedir. Termostat ile sistemin kurutma havası istenilen sıcaklık değerine ayarlanabilmekte ve sistemde kullanılan fan termostat kontrollü olarak sabit hava hızında üfleme yapabilmektedir. Kurutma kabini sicaklığının ayarlanan değerden düşük olduğu durumlarda, termostat tarafindan kontrol edilen pompa devreye girmektedir ( 2 numaralı selenoid açar ve 3 numaralı selenoid kapatır). Kurutma havası sıcaklı̆̆ı, ayarlanan değerden yüksek olduğunda ise; pompa devreden çıkmaktadır (3 numaralı selenoid açar ve 1sı kolektörden depoya akmaya başlar). Aynı zamanda pompa durduğundan; üretilen elektrik enerjisi akülere, 1s1 enerjisi ise su deposuna yönlendirildiğinden, sistemin gece kullanımı için 1s1 ve elektrik enerjisi depo edilmiş olmaktadır. Böylece sistemde kurutma işleminin sürekliliği sağlanmıştır.

Sistemde domates kurutulması için uygun olan şartların (kurutma havası sıcaklığ 1 ve kurutma havası hızı) alt ve üst sınır değerleri sistem tasarımı yapılırken göz önünde bulundurulmuş ve sistem imalatında kullanılan ekipmanların kapasiteleri kurutma şartlarına uygun olarak belirlenmiştir. Güneş enerjisi destekli kurutma sisteminde kullanılan ekipmanların özellikleri Çizelge 1'de ve deneyler esnasında kullanılan cihazların teknik özellikleri ise Çizelge 2'de verilmiştir. Ayrıca belirsizlik analizi yapılarak sonuçları Çizelge 2'de verilmiştir. Isı değiştiricinin önü ve arkası, hava klapelerinin arkası ve kurutma odası çıkışı sıcaklık ve nem ölçüm noktaları (T), kurutma firını girişi ise hız ölçüm (H) noktasıdır (Şekil 1).

\section{Çizelge 1- Sistem ekipmanları ve özellikleri}

Table 1-System equipment and properties

\begin{tabular}{|c|c|}
\hline Kullanılan Ekipmanlar & Teknik Özellikleri \\
\hline Pompa & Maksimum 10 bar, 3 kademeli, $60-83-110 \mathrm{~W}, 230 \mathrm{~V}-50 \mathrm{~Hz}, 130 \mathrm{~mm}$ \\
\hline Fan & $40 \mathrm{~W}, 220 \mathrm{~V}, 2700 \mathrm{~min}^{-1}$ \\
\hline Is1 değiştirici & $1 / 2 \mathrm{HP}$, bakır borulu, alüminyum kanatçıklı \\
\hline Depo & Su kapasitesi 200 litre \\
\hline Selenoid valfler & 3/4", T-GM 104A, 17 mm 0.5-16 Bar \\
\hline Bataryalar (aküler) & 12V 40 Ah, PB12040.0 \\
\hline Güneş panelleri (PV) & Maksimum güç ve voltaj1 $40 \mathrm{~W}-17.6 \mathrm{~V}, 535 \times 635 \times 35(\mathrm{~mm})$, tolerans $( \pm 5 \%)$ \\
\hline Güneş kolektörü & Maksimum sıcaklık $200^{\circ} \mathrm{C}$, çalışma basıncı 6 bar, test basınc1 9 bar, akışkan kapasitesi 4.2 litre \\
\hline İnvertör (driver) & Giriş $12 \mathrm{~V}$, çıkış $220 \mathrm{~V} 50 \mathrm{~Hz}$, sürekli $300 \mathrm{~W}$, DC-AC12V-220 \\
\hline Termostat & $0-90{ }^{\circ} \mathrm{C}, 16 \mathrm{~A}-240 \mathrm{~V}$ \\
\hline
\end{tabular}

\section{Çizelge 2- Deneyler esnasında kullanılan cihazlar ve özellikleri}

Table 2-Properties of equipment that used during experiments

\begin{tabular}{llll}
\hline Kullanılan cihazlar & Teknik Özellikleri & Hassasiyet & Toplam Belirsizlik \\
\hline Dijital tartı & Maksimum $6100 \mathrm{~g}$ & $\pm 0.01 \mathrm{~g}$ & $\pm 0.014 \mathrm{~g}$ \\
Hava hızı ve sıcaklık ölçüm cihazı & $-20 \sim 70{ }^{\circ} \mathrm{C}, 0-20 \mathrm{~m} \mathrm{~s}^{-1}$, & $\pm 0.01 \mathrm{~m} \mathrm{~s}^{-1}$ & $\pm 0.017 \mathrm{~m} \mathrm{~s}^{-1}$ \\
& NTC sensör & $\pm 0.1{ }^{\circ} \mathrm{C}$ & $\pm 0.14{ }^{\circ} \mathrm{C}$ \\
Sicaklık ve nem ölçüm cihazı & $\% 5 \sim 95 \mathrm{RH}, 0 \sim 50{ }^{\circ} \mathrm{C}$ & $\pm \% 3 \mathrm{RH}$ & $\pm 0.042 \mathrm{RH}$ \\
Dijital solar metre & DS-05A, $0-1200 \mathrm{~W} \mathrm{~m}^{-2}$ & $\pm \% 3 \mathrm{~W} \mathrm{~m}^{-2}$ & $\pm 0.7^{\circ} \mathrm{C}$ \\
\hline
\end{tabular}




\subsection{Kuru madde tayini}

Kurutma başlangıcında üründeki nem içeriğinin belirlenebilmesi için kuru madde tayininin yapılması gerekir. Deneylerde kullanılmak üzere temin edilen domateslerin, aşağıdaki işlemler gerçekleştirilerek kuru madde tayini yapılmıştır.

Domateslerin sapları alınarak dilimleme makinesi ile $5 \mathrm{~mm}$ kalınlığında dilimlenmiştir. Numuneler öncelikle $103 \pm 2{ }^{\circ} \mathrm{C}$ 'de sabit tutulabilen bir etüv firınında her yarım saatte bir tartılarak, birbirini takip eden iki ölçüm sonunda ürün ağırlığı \% 1'den az olduğunda domatesler kuru kabul edilmiştir (AOAC 1990). Bu işlem 3 ayrı numune için ayrı ayrı yapılmıştır. Yapılan bu işlemlerin sonucunda ortalama değer alınarak Eşitlik 14 ile ürünün kuru ağırlığa göre nem içeriği bulunmuştur.

\subsection{Domateslerin kurutulmasl}

Başlangıç nem miktarları belirlenen dilimlenmiş domatesler, güneş enerjisi destekli kurutucuda kurutma kabinine yerleştirilerek, kurutma işlemine hazır hale getirilmiştir. Kurutmaya hazır hale getirilen domatesler, daha önce hazırlanan kurutma şartlarında kurutulmaya başlanılmıştır.

İnsan beslenmesinde domates ürünleri, likupenin ana kaynağıdır. Likupenin prostat ve göğüs kanserine ve ateroskleroza karşı koruduğu, yüksek yoğunluklu lipoprotein oksidasyonunu azalttığ1 ve kan kolesterol seviyelerini azaltmaya yardımcı olduğu bilinmektedir (Kerkhofs et al 2005; Xianquan et al 2005).

Lee \& Chen (2002) tarafindan $50{ }^{\circ} \mathrm{C}$ 'de 12 saatte yapilan 1sitmada likupen konsantrasyonunun etkilenmediği, buna karşın $100{ }^{\circ} \mathrm{C}$ 'de 2 saatlik 1sitmanın likupende \% 78'lik azalmaya neden olduğu ifade edilmiştir. Ayrıca, Marfil et al (2008) tarafindan domatesin kuruma esnasinda $60{ }^{\circ} \mathrm{C}$ 'nin altındaki kurutma havası sicaklıkları askorbik asit bozulmasının azaltılmasına yardımcı olabildiği belirtilmiştir. $\mathrm{Bu}$ ve benzeri nedenlerle sistem, kurutulan domateslerde isı hasarlarından kaçınmak için (besinsel bozulma, esmerleşme vb.) $40{ }^{\circ} \mathrm{C}, 45$ ${ }^{\circ} \mathrm{C}$ ve $50{ }^{\circ} \mathrm{C}$ sıcaklıklarda test edilmiştir.
Yapılacak kurutma uygulamasında yüksek hava hızı sistem kapasitesini ve enerji tüketimini arttırırken kurutma süresi de kısalabilecektir. $\mathrm{Bu}$ nedenle çalışmada $5 \mathrm{~mm}$ kalınlığında dilimlenmiş domatesler tamamıyla güneş enerjisiyle çalışan kurutma sisteminde $0.2 \mathrm{~m} \mathrm{~s}^{-1}$ hava hizında kurutulmuştur. $\mathrm{Bu}$ çalışma, kurutma havası hızı açısından diğer çalışmalar ile karşılaştırıldığında; domatesler, bazı çalışmalardan daha düşük $(>0.2$ $\left.\mathrm{m} . \mathrm{s}^{-1}\right)$ veya daha yüksek $\left(<0.2 \mathrm{~m} \mathrm{~s}^{-1}\right)$ hava hızında (Donald 2008) ya da aynı hava hızında $\left(=0.2 \mathrm{~m} \mathrm{~s}^{-1}\right)$ (Demiray et al 2013) kurutulmuştur.

Sistemin uygulanabilirliği açısından, farklı şartlarda güneş enerjisiyle $40{ }^{\circ} \mathrm{C}, \quad 45{ }^{\circ} \mathrm{C}$ ve $50 \quad{ }^{\circ} \mathrm{C}$ sicaklıklara ulaşabilme ve sistem 1 s1 kayıplarının azaltılması gibi faktörler göz önünde bulundurulmuştur. Ürünün yüksek sıcaklıklara maruz bırakılmasından ziyade güneş enerjisiyle kolayca uygulanabilen gerektiğinde küçük ya da büyük ölçekli bir kurutma ünitesi düşünülmüştür.

\subsection{Kurutma işleminin sonlandırılması}

Yapılan kurutma işlemlerinde her bir deney $40{ }^{\circ} \mathrm{C}$, $45^{\circ} \mathrm{C}$ ve $50^{\circ} \mathrm{C}$ sıcaklık için yapılmış ve ürünler son denge nemi miktarına ulaştığında kurutma işlemi sonlandırılmıştır. Kurutma deneylerinde domateslerde; son nem miktarları ve duyusal analiz gibi hususlar göz önünde bulundurularak işlemler yapılmıştır.

\section{Bulgular ve Tartışma}

Bu çalışmada literatürden farklı olarak, sistemde deneyler esnasında güneş enerjisinin yetersiz olduğu zaman dilimlerinde depolanan enerji kullanılarak güneş enerjisi ile sürdürülebilir bir kurutma sistemi hayata geçirilmiş ve sistem analiz edilmiştir.

Yapılan deneylerin sonuçlarına göre; öncelikle dilimlenmiş domateslerin ilk ve son nem içeriği kuru esasa göre Eşitlik 14'ten başlangıç nemi 16.39 g su g kuru madde ${ }^{-1}$, son nem miktarı $0.21 \mathrm{~g}$ su g kuru madde ${ }^{-1}$ olarak hesaplanmıştır. Başlangıç nem miktarı belirlenen domatesler, farklı kurutma havasi sicaklıklarında $\left(40{ }^{\circ} \mathrm{C}, 45^{\circ} \mathrm{C}\right.$ ve $\left.50{ }^{\circ} \mathrm{C}\right)$ ve $0.2 \mathrm{~m} \mathrm{~s}^{-1}$ hava hızında güneş enerjili sürekli kurutma 
firınında kurutulmuştur. Kurutma işlemi esnasında kurutma süresine bağlı olarak ürün nemi içeriğinin değişimi Şekil 3'de gösterilmektedir. Buna göre; kurutma işleminde, başlangıçta ürün içerisindeki serbest nemin hızlı olarak uzaklaştığı ve ilerleyen safhalarında ise, nem uzaklaşma hızının daha yavaş olduğu görülmüştür. Bu da ürün içinde serbest nem kolay alınırken ürün içindeki nemin uzaklaşmasının biraz daha enerji ve zaman istediğini göstermektedir. Kurutma işlemi esnasında kurutma süresine bağlı olarak ürün nem oranı ve $\mathrm{g}$ su $\mathrm{g}$ kuru madde ${ }^{-1}$ $\min ^{-1}$ olarak kuruma hızı değişimi Şekil 4 ve 5 'de gösterilmektedir.

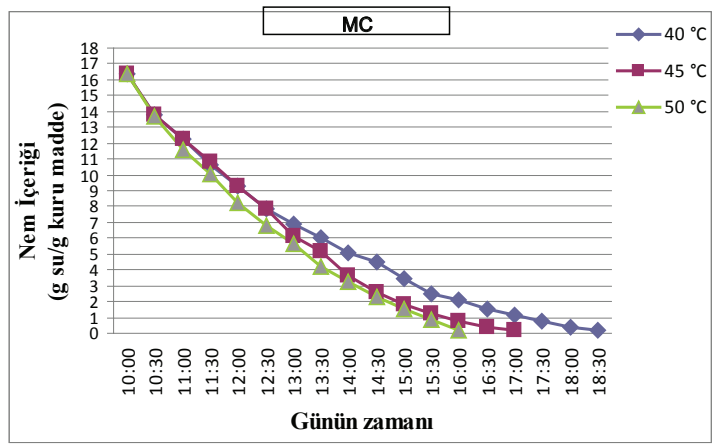

Şekil 3- Domateslerdeki nem miktarının kurutma süresine göre değişimi

Figure 3- Variation of tomato moisture content in drying time

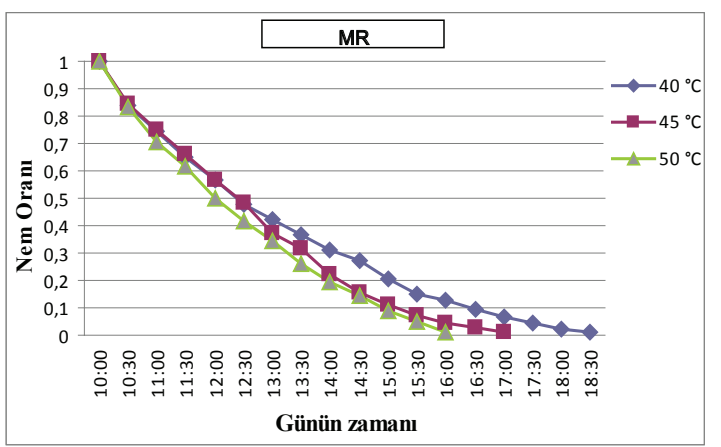

Şekil 4- Kurutma süresine göre nem oranı değerleri Figure 4- Moisture ratio values according to drying time

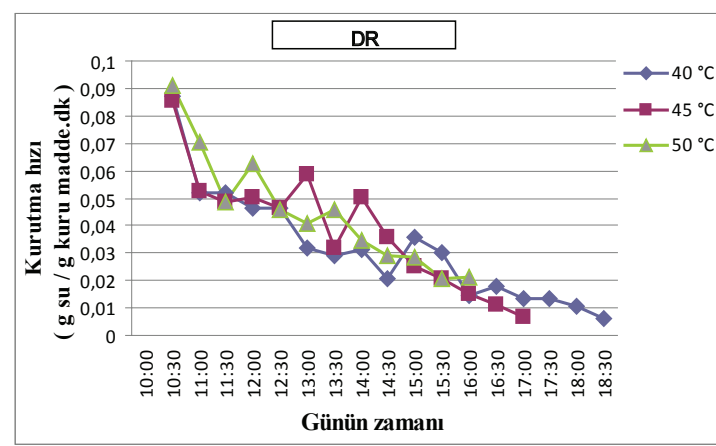

Şekil 5- Kurutma süresine göre kurutma hızı değerleri

Figure 5-Drying rate values according to drying time

Şekil 6'da güneş kolektörü su çıkış sıcaklıklarının kurutma süresine göre değişimi verilmiştir. Kolektör çıkış sıcaklıkları saat 11:00 ile 14:00 arasında en yüksek sıcaklık değerlerine ulaşmıştır. Deneyler sırasında güneş 1şınım şiddetine bağlı olarak kolektör çıkış sıcaklıklarında dalgalanmalar olmuştur. Kurutma havası sıcaklığının istenilen kurutma değerine ayarlanması kolektör çıkış sıcaklığının ayarlanan sıcaklığın üstünde olmasını gerektirdiğinden $50^{\circ} \mathrm{C}$ 'de yapılan deneyde hava şartlarının uygun olmaması nedeniyle depodaki su sıcaklığı arttırılamamıştır. Yapılan hesaplamalarda depolanan sicak suyun $30{ }^{\circ} \mathrm{C}$ 'ye soğuyana kadar sistemde kullanılacağı göz önünde bulundurulmuştur.

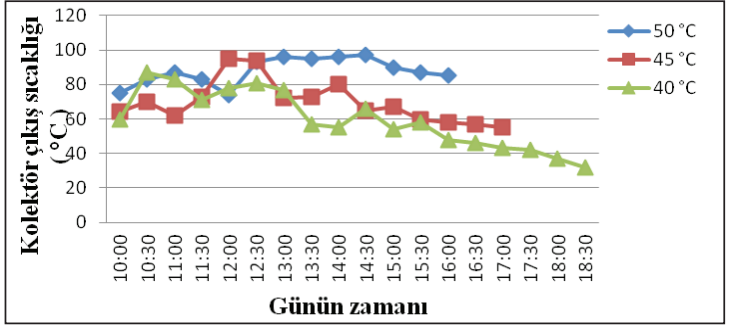

Şekil 6- Kolektör çıkış suyu sıcaklıklarının kurutma süresine göre değişimi

Figure 6- Variation of collector water outlet temperature in drying time 
Depo suyu sicaklığı, $40{ }^{\circ} \mathrm{C}^{\prime}$ de yapılan deney sırasında en yüksek değere ulaşmıştır (Şekil 7). Kurutmanın sonlarına doğru güneş enerjisinin azalmasından dolayı depodaki sıcak su 1sı kaynağı olarak kullanılmıştır. Deneylerde depolanan 1S1 enerjisi Eşitlik 8 'den $40{ }^{\circ} \mathrm{C}$ 'de $4.651 \mathrm{kWh}, 45$ ${ }^{\circ} \mathrm{C}$ 'de $4.069 \mathrm{kWh}$ ve $50{ }^{\circ} \mathrm{C}$ 'de $3.197 \mathrm{kWh}$ olarak hesaplanmıştır.

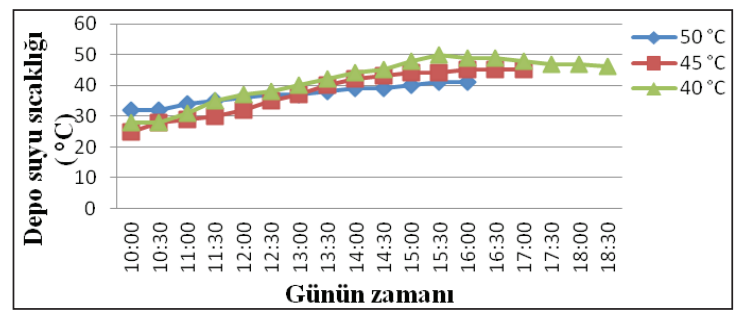

Şekil 7- Depo su sıcaklığının kurutma süresince değişimi

Figure 7- Variation of tank water temperature in drying time

Güneş enerjili süreklikurutucuda güneş kolektörü tarafından sağlanan ısı enerjisi Şekil 8'de verilmiştir. Buna göre; $0.2 \mathrm{~m} \mathrm{~s}^{-1}$ hava hızında kurutma işlemi esnasinda $40{ }^{\circ} \mathrm{C}$ 'de $1.908 \mathrm{kWh}, 45{ }^{\circ} \mathrm{C}$ 'de 2.043 $\mathrm{kWh}, 50{ }^{\circ} \mathrm{C}$ 'de $2.237 \mathrm{kWh}$ enerji kullanılmıştır. Kurutma işleminde başlangıçta kullanılan enerji; kurutma kabininin 1sıttılması ve ürün içerisindeki serbest nemin başlangıçta hızlı buharlaşmasından dolayı fazladır. Kurutma işleminin sonuna doğru 1sı değiştiricisinden sisteme verilen 1s1 enerjisi, ürün içerisindeki nemin azalmasından dolayı azalmıştır.

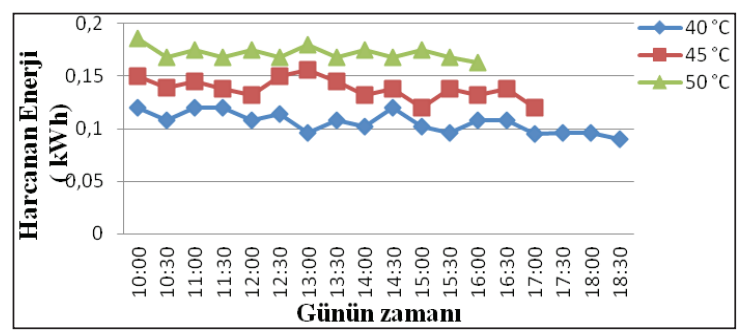

Şekil 8- Kurutma için harcanan enerji miktarının kurutma süresince değişimi

Figure 8-Variation of consumed energy for drying in drying time
Bu çalışma ile literatürde yapılan çalışmalardan farklı olarak, güneş enerjili kurutucuların tamamıyla güneş enerjisiyle çalışabilmesi ve buna bağlı kurutma sistemi verimliliği deneysel olarak analiz edilmiştir. Güneşli zamanlarda elektrik ve 1s1 enerjisinin depolanması ile gece ya da güneş ışınımının az olduğu zamanlarda domates kurutulmasinda kurutma havası için istenilen psikrometrik şartlar sağlanmıştır. Böylece pratik ve kullanıcıların tercih edebilecekleri bir güneş enerjili domates kurutucusu ortaya konulmuştur.

Kurutma işlemi esnasında kurutma havasına uygulanan işlemler Şekil 9'da psikrometrik diyagram üzerinde gösterilmiştir. Buna göre; 1 şartlarındaki dış hava ile 2 şartlarındaki hava, \% 50 oranında karıştırılarak 3 konumuna gelir. 3 konumundaki karışım havası 1sı değiştiricisinden geçerek duyulur olarak isitılır ve istenilen kurutma havası değerine gelerek 4 konumunda kurutma odasına girmektedir. Egzoz havasının \% 50'si dişarı atılıp \% 50'si taze hava ile karışarak (1-2 konumundan 3 noktasinda) tekrar sisteme girmektedir. Isıt1larak nem alma kapasitesi artan hava (3-4 konumu), ürün üzerinden geçtiğinden bir miktar bağıl nemi artarken sıcaklığı da düşmektedir. Ürün üzerinden geçen hava, kurutma kabininde $(\Delta w)$ kadar nemi bünyesine alarak (4-2 konumu) dışarıya atılır.

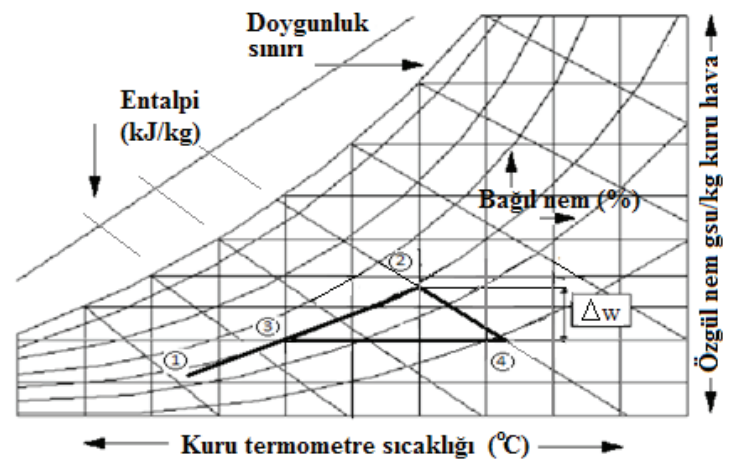

Şekil 9- Kurutma sisteminin psikrometrik analizi: 1, dış hava; 2, dönüş havası; 3, karışım havasıı (ISı değiştirici öncesi); $\mathbf{4}$, kurutma kabinine üflenen hava Figure 9- Psychometric analysis of the drying system: 1, outside air; 2, return air; 3, mixed air; 4, blown air to drying cabinet 


\section{Sonuçlar}

$\mathrm{Bu}$ çalışma ile aşağıda belirtilen sonuç ve önerilere ulaşılmıştır.

- $5 \mathrm{~mm}$ kalınlığında dilimlenmiş domatesler 50 ${ }^{\circ} \mathrm{C}, 45{ }^{\circ} \mathrm{C}, 40{ }^{\circ} \mathrm{C}$ kurutma havası sicaklığ 1 ve ortalama $0.2 \mathrm{~m} \mathrm{~s}^{-1}$ hava hizında sirasiyla 6,7 ve 8.5 saatte kurutulmuştur. Deneylerde, kurutma havası sıcaklığ1 düştükçe kurutma süresinin arttığ1 görülmüştür. Yapılan deneylerde kurutma süresinin literatürdeki çalışmalardan daha kısa sürede olmasının nedeni kurutmanın başlangıcında domateslerin $5 \mathrm{~mm}$ kalınlığında dilimlenmesidir.

- Kurutma sisteminin güneş enerjili olmasından dolayı, enerji tüketim maliyeti olmamıştır.

- Kurutma sisteminde güneşten gelen enerji, 1S1 enerjisi ve elektrik enerjisi olarak kullanılmış ve depolanmıştır. Kurutma için gerekli olan enerjinin fazlası sıcak su deposuna 1s1 enerjisi olarak ve akülere de elektrik enerjisi olarak depolanı, gerektiğinde sistemin sürekli çalıştırılması sağlanmıştır.

- Yapilan duyusal analizler sonucunda, her bir kurutma havası sicaklığında kurutulan ürünlerin kurutma sonrası tadında ve renginde bir bozulma görülmemiştir.

- Sistemde harcanan ve depolanan 1S1 enerjisi Eş. 8'den hesaplanarak kurutmada harcanan is1 enerjisi; $40{ }^{\circ} \mathrm{C}^{\prime}$ de $1.908 \mathrm{kWh}, 45{ }^{\circ} \mathrm{C}$ 'de 2.043 $\mathrm{kWh}$ ve $50{ }^{\circ} \mathrm{C}$ 'de $2.237 \mathrm{kWh}$ 'tır. Depolanan 1s1 enerjisi; $40{ }^{\circ} \mathrm{C}$ 'de $4.651 \mathrm{kWh}, 45{ }^{\circ} \mathrm{C}$ 'de $4.069 \mathrm{kWh}, 50 \quad{ }^{\circ} \mathrm{C}$ 'de $3.197 \mathrm{kWh}$ olarak hesaplanmıştır. Harcanan ve depolanan enerjiler karşılaştırıldığında bu sistem ile kurutmanın depolanan enerji ile gece devam edebileceği görülmüştür.

- Domatesler, 16.39 g su g kuru madde ${ }^{-1}$ başlangıç nem miktarından $0.21 \mathrm{~g}$ su g kuru madde ${ }^{-1}$ son nem miktarına kadar kurutulmuştur.

- Deney sonuçlarına göre SMER değerleri sirasiyla $0.49 \mathrm{~kg} \mathrm{kWh}^{-1}, 0.45 \mathrm{~kg} \mathrm{kWh}^{-1}$ ve 0.42 $\mathrm{kg} \mathrm{kWh}^{-1}$ olarak hesaplanmıştır.
Bu çalışmada, daha önceki birçok çalışmada denenmiş sıcaklıklardan daha düşük kurutma havası sıcaklıklarında domatesler kurutulmuştur. Düşük sıcaklıklarda yapılan kurutma uygulamaları ile domateslerde oluşabilecek 1S1 hasarlarının (likupen azalması, esmerleşme vb.) önüne geçilmiş buna bağlı olarak kaliteli bir şekilde domatesler kurutulmuştur.

Domateslerin $\quad 5 \quad \mathrm{~mm} \quad$ kalınlığında dilimlenmesinden dolayı kurutma esnasında üründen kurutma havasına kütle transferi hızlanmış ve diğer çalışmalara göre domatesler daha kısa sürede kurutulmuştur.

Deneysel olarak analiz edilen domates kurutma sistemi enerjisini tamamen güneş enerjisinden üreten ve $10 \mathrm{~kg}$ kapasitesi olan bir sistemdir. Sistemin ilk yatırım maliyeti öncelikle sistemin kapasitesine daha sonra da sistemin verimliliğine bağlıdır. Sistemin verimliliğine etki eden unsurlar güneş kolektörü ve güneş pili verimleri, kurutma odası şekli ve yalıtımı, pompa ve fan verimleri olarak sayılabilir. Sistemin ilk yatırım maliyeti kurutma kapasitesine bağlı olarak belirlenen sistem ekipmanlarının maliyetidir. Sistemin enerji giderleri olduğunca az olup, çoğu zaman diliminde sistem kendi enerjisini üretecektir. Gerektiğinde, üretilen enerji kurutma dışındaki diğer uygulamalarda da kullanılabilecektir. $\mathrm{Bu}$ sistem küçük ve büyük ölçekte pratik bir şekilde uygulanabilir ve böylece konvansiyonel kurutma sistemlerine alternatif olabilir.

$\mathrm{Bu}$ çalışma ile domatesin kurutulmasına yönelik mevcut sistemlere enerji verimliliği açısından alternatif olabilecek bir sistem test edilmiş ve kullanılabilirliği ortaya konulmuştur. Bu çalışmada elde edilen sonuçlar göstermiştir ki; sistemde, kullanılan enerji tamamıla güneş enerjisi ile sağlanarak, günümüz enerji sistemlerini ve çevresel etkilerini incelediğimizde bu sistem kurutma sistemlerine örnek teşkil edecek ve yenilikler getirecektir. 


\begin{tabular}{|c|c|c|c|}
\hline \multicolumn{4}{|c|}{ Kisaltmalar ve Semboller } \\
\hline A & Firın toplam duvar yüzey alanı, $\mathrm{m}^{2}$ & $\mathrm{~T}_{\text {iç }}$ & $\begin{array}{l}\text { Kurutmaya başlamadan önceki iç hava } \\
\text { S1cakl } 1 \breve{g}_{1},{ }^{\circ} \mathrm{C}\end{array}$ \\
\hline $\mathrm{c}_{1}$ & Fırın duvarlarının özgül ısısı, $\mathrm{kJ} \mathrm{kg}^{-1} \mathrm{~K}^{-1}$ & $\mathrm{Td}$ & Diş hava sıcaklığ $1,{ }^{\circ} \mathrm{C}$ \\
\hline$c_{2}$ & Havanın özgül 1sısı, $\mathrm{kJ} \mathrm{kg}^{-1} \mathrm{~K}^{-1}$ & $\mathrm{~V}$ & Hava miktarı, $\mathrm{m}^{3}$ \\
\hline $\mathrm{c}_{3}$ & Domatesin özgül 1sıs1, $\mathrm{kJ} \mathrm{kg}^{-1} \mathrm{~K}^{-1}$ & $\Delta w$ & Özgül nem fark1, g su kg kuru hava-1 \\
\hline $\mathrm{d}$ & Malzeme kalınlığı, m & $\mathrm{x}$ & Bağımsız değişken \\
\hline $\mathrm{F}_{\mathrm{k}}$ & Kolektör yüzey alanı, m² & $\mathrm{W}_{\mathrm{R}}$ & R büyüklüğünün toplam belirsizliği \\
\hline h & Entalpi, kJ kg-1 & $\mathrm{w}$ & Hata oran 1 \\
\hline $\mathrm{I}_{\text {TOP }}$ & 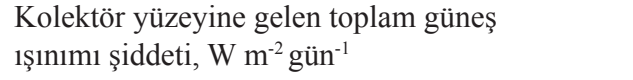 & $\mathrm{Z}$ & Kurutma süresi, h \\
\hline $\mathrm{K}$ & $\begin{array}{l}\text { Firın duvarlarının toplam 1sı geçiş katsayısı, W } \\
\mathrm{m}^{-2} \mathrm{~K}^{-1}\end{array}$ & $\alpha_{\text {iç }}$ & İç yüzey $1 \mathrm{~s} 1$ taşınım katsayısı, $\mathrm{W} \mathrm{m}^{-2} \mathrm{~K}^{-1}$ \\
\hline$M$ & Nem içeriği, g su g kuru madde ${ }^{-1}$ & $\alpha_{\mathrm{d} ı s ̦}$ & D1ş yüzey 1sı taşınım katsayısı, $\mathrm{W} \mathrm{m}^{-2} \mathrm{~K}^{-1}$ \\
\hline$M_{\mathrm{e}}$ & Denge nemi içeriği, g su g kuru madde ${ }^{-1}$ & $\lambda$ & $\begin{array}{l}\text { Duvarları oluşturan her bir katmanın 1s1 } \\
\text { iletim katsayıs1, } \mathrm{W} \mathrm{m}^{-2} \mathrm{~K}^{-1}\end{array}$ \\
\hline$M_{0}$ & İlk nem içeriği, g su g kuru madde ${ }^{-1}$ & $\Delta \mathrm{T}$ & Sicaklık fark1, ${ }^{\circ} \mathrm{C}$ \\
\hline$M_{t}$ & $\begin{array}{l}\text { " } \mathrm{t} \text { ” zamanda nem içeriği, g su g kuru } \\
\text { madde }^{-1}\end{array}$ & $\rho$ & Havanın yoğunluğu, $\mathrm{kg} \mathrm{m}^{-3}$ \\
\hline$M_{t+d t}$ & "t+dt" zamanda nem içeriği, g su g kuru madde ${ }^{-1}$ & $\mathrm{i}$ & Giriş \\
\hline$\dot{m}_{s u}$ & Domateslerden çekilen su kütlesi, $\mathrm{kg} \mathrm{s}^{-1}$ & ia & Giriş havas1 \\
\hline$m_{d}$ & Kurutulan domateslerin kütlesi, $\mathrm{kg}$ & $\mathrm{DR}$ & Kuruma hızı, g su g kuru madde ${ }^{-1} \min ^{-1}$ \\
\hline $\mathrm{m}$ & Kütle, kg & EIE & Elektrik İşleri Etüt İdaresi \\
\hline$\eta$ & Verim, $\%$ & KA & Kuru ağırlık, kg \\
\hline$Q_{T}$ & Sistemde suda depolanan ve harcanan enerji, kJ & $\mathrm{MC}$ & Nem içeriği, g su g kuru madde ${ }^{-1}$ \\
\hline$Q_{d}$ & Sistemde depolanan enerji, $\mathrm{kJ}$ & $M C_{K A}$ & $\begin{array}{l}\text { Üründeki kuru ağırlığa göre nem oranı, g su g } \\
\text { kuru ağırlık }{ }^{-1}\end{array}$ \\
\hline$Q_{h}$ & Kurutucuda harcanan enerji, kJ & $M C_{Y A}$ & $\begin{array}{l}\text { Üründeki yaş ağırlığa göre nem oranı, g su g } \\
\text { yaş ağırlık }\end{array}$ \\
\hline$\dot{Q}$ & $\begin{array}{l}\text { Birim zamanda güneş kolektöründen elde edilen } \\
\text { enerji, } \mathrm{kJ} \mathrm{s}^{-1}\end{array}$ & MR & Ayrılabilir nem oranı \\
\hline $\mathrm{Q}_{\mathrm{VTOP}}$ & Kurutma işlemi için gerekli toplam enerji, kJ & NA & Normalde açık \\
\hline $\mathrm{R}$ & Ölçülmesi gereken büyüklük & NK & Normalde kapalı \\
\hline $\mathrm{r}_{\mathrm{o}}$ & Suyun buharlaşma $1 \mathrm{~s} 1 \mathrm{~s} 1, \mathrm{~kJ} \mathrm{~kg}^{-1}$ & $S M E R$ & Özgül nem çekme oranı, kg kWh-1 \\
\hline $\mathrm{T}_{\mathrm{k}}$ & Kurutma firınının işletme sıcaklığ $1,{ }^{\circ} \mathrm{C}$ & YA & Yaş ağırlık, kg \\
\hline
\end{tabular}

\section{Kaynaklar}

Aktaş M, Ceylan İ \& Doğan H (2004). Güneş enerjili kurutma sistemlerinin findik kurutulmasina uygulanabilirliği. Teknoloji Dergisi 7(4): 557-564

Aktaş M, Ceylan İ \& Doğan H (2005). Isı pompalı endüstriyel findık kurutma firınının modellenmesi. Politeknik Dergisi 8(4): 329-336

Aktaş M (2007). Isı pompası destekli find1k kurutma firınının tasarımı, imalatı ve deneysel incelenmesi.
Doktora Tezi, Gazi Üniversitesi Fen Bilimleri Enstitüsü (Yayımlanmamış), 60, Ankara

Al-Muhtaseb A H, Al-Harahsheh M, Hararah M \& Magee T R A (2010). Drying characteristics and quality change of unutilized-protein rich-tomato pomace with and without osmotic pre-treatment. Industrial Crops and Products 31: 171-177

AOAC 1990. Official Method of Analysis, Association of Official Analytical Chemist, IAC, Arlington, Virginia 
Ashrae (1993). Tarım ürünlerinin kurutulmasında ve depolanmasında göz önüne alınacak fizyolojik etkenler, Temel El Kitabı Bölüm 10. Tesisat Mühendisleri Derneği Teknik Yayınlar 2, 10-15

Cernişev S (2010). Effects of conventional and multistage drying processing on non-enzymatic browning in tomato. Journal of Food Engineering 96: 114-118

Ceylan İ \& Aktaş M (2008). Isı pompası destekli bir kurutucuda findik kurutulması. Gazi Üniversitesi Mühendislik Mimarlık Fakültesi Dergisi 23(1): 215-222

Chang C H, Lin H Y, Chang C Y \& Liu Y C (2006). Comparisons on the antioxidant properties of fresh, freeze-dried and hot-air-dried tomatoes. Journal of Food Engineering 77(3): 478-485

Çitıroğlu A (2000). Güneş enerjisinden yararlanarak elektrik üretimi. Mühendis ve Makina 485:41: 32-33

Demiray E, Yahya T \& Y1lmaz Y (2013). Degradation kinetics of lycopene, b-carotene and ascorbic acid in tomatoes during hot air drying. LWT - Food Science and Technology 50: 172-176

Donald G M (2008). Chapter 4, Solar Drying in Developing Countries (Ed: Gordon Robertson \& John Lupien), Possibilities and Pitfalls, Using Food Science and Technology to Improve Nutrition and Promote National Development: Selected Case Studies., International Union of Food Science \& Technology, Ontario, Canada

Doymaz İ (2007). Air-drying characteristics of tomatoes. Journal of Food Engineering 78(4): 1291-1297

El-Sebaii A A, Aboul-Enein S, Ramadan, M R I \& ElGohary H G (2002). Empirical correlations for drying kinetics of some fruits and vegetables. Energy 27(9): 845-859

EİE (Elektrik İşleri Etüt İdaresi Genel Müdürlüğü) (2011). Güneş enerjisi çalışmaları. http://www.eie. gov.tr/turkce/YEK/gunes/tgunes.html

Gallali Y M, Abujnah Y S \& Bannani F K (2000). Preservation of fruits and vegetables using solar dryer: A comparative study of natural and solar drying. Renewable Energy 19: 203-212

Giovanelli G, Zanoni B, Lavelli V \& Nani R (2002). Water sorption, drying and antioxidant properties of dried tomato products. Journal of Food Engineering 52(2): 135-141

Kavak Akpinar E (2010). Drying of mint leaves in a solar dryer and under open sun: Modelling, performance analyses. Energy Conversion and Management 51: 2407-2418

Kerkhofs N S, Lister C E \& Savage G P (2005). Change in colour and antioxidant content of tomato cultivars following forced-air drying. Plant Foods for Human Nutrition 60: 117-121

Lee M T \& Chen B H (2002). Stability of lycopene during heating and illumination in a model system. Food Chemistry 78: 425-432

Lutz K, Mühlbauer W, Müller J \& Reisinger G (2003). Development of a multipurpose solar crop dryer for arid zones. Institute of Agricultural Engineering Hohenheim, Germany

Marfil P H M, Santos E M \& Telis V R N (2008). Ascorbic acid degradation kinetics in tomatoes at different drying conditions. LWT Food Science and Technology 41: $1642-1647$

Mengeş H O (2001). Konya bölgesinde yetiştirilen vişne ve kayısıların kontrollü şartlar altında kuruma karakteristiklerinin belirlenmesi. Tarımsal Mekanizasyon 20. Ulusal Kongresi, Şanlıurfa

Midilli A \& Küçük H (2003). Mathematical modeling of thin layer drying of pistachio by using solar energy. Energy Conversion and Management 44(7): 1111-1122

Mutlu A (2007). Tokat'ta güneş enerjili raflı kurutucu ile domates kurutma koşullarının belirlenmesi. Yüksek Lisans Tezi, Gazi Osman Paşa Üniversitesi Fen Bilimleri Enstitüsü Tarım Makineleri Anabilim Dalı (Yayımlanmamış), Tokat

Okuyan C (1997). Güneş enerjisiyle tarımsal ürün kurutulmas1. Harran Üniversitesi Ziraat Fakültesi Dergisi 3, Şanliurfa

Pitts D R \& Sissom L E (1977). Theory and problems of heat transfer. McGraw-Hill Book Company, 200

Saçılık K, Keskin R \& Eliçin A K (2006). Mathematical modelling of solar tunnel drying of thin layer organic tomato. Journal of Food Engineering 73(3): 231-238

Santos-Sánchez N F, Valadez-Blanco R, GómezGómez M S, Pérez-Herrera A \& Salas-Coronado R (2012). Effect of rotating tray drying on antioxidant components, color and rehydration ratio of tomato saladette slices. LWT - Food Science and Technology 46: 298-304

Shariah A, Al-Akhras M A \& Al-Omari I A (2002). Optimizing the tilt angle of solar collectors. Renewable Energy 26: 587-598

Şevik S (2011). Isı Pompası ve Güneş Kolektörünün Birlikte Kullanıldığı, Isıtma ve Kurutma Amaçlı Sıcak Hava Üretim Sisteminin Tasarımı, İmalatı ve Deneysel İncelenmesi. Doktora Tezi, Gazi Üniversitesi Fen Bilimleri Enstitüsü (Yayımlanmamış), Ankara

Xianquan S, Shi J, Kakuda, Y \& Yueming J (2005). Stability of lycopene during food processing and storage. Journal of Medicinal Food 8: 413-422 